\title{
Yield of Image-Guided Needle Biopsy for Infectious Discitis: A Systematic Review and Meta-Analysis
}

\author{
(D) A.L. McNamara, (DE.C. Dickerson, DD.M. Gomez-Hassan, (DS.K. Cinti, and (D) A. Srinivasan
}

\begin{abstract}
BACKGROUND: Image-guided biopsy is routinely conducted in patients with suspected discitis, though the sensitivity reported in the literature ranges widely.
\end{abstract}

PURPOSE: We applied a systematic review and meta-analysis to estimate the yield of image-guided biopsy for infectious discitis.

DATA SOURCES: We performed a literature search of 4 data bases: PubMed, Cochrane CENTRAL Register of Controlled Trials, Embase.com, and Scopus from data base inception to March 2016.

STUDY SELECTION: A screen of 1814 articles identified 88 potentially relevant articles. Data were extracted for 33 articles, which were eligible if they were peer-reviewed publications of patients with clinical suspicion of discitis who underwent image-guided biopsy.

DATA ANALYSIS: Patients with positive cultures out of total image-guided biopsy procedures were pooled to estimate yield with $95 \%$ confidence intervals. Hypothesis testing was performed with an inverse variance method after logit transformation.

DATA SYNTHESIS: Image-guided biopsy has a yield of approximately 48\% (793/1763), which is significantly lower than the open surgical biopsy yield of $76 \%$ (152/201; $P<.01)$. Biopsy in patients with prior antibiotic exposure had a yield of 32\% (106/346), which was not significantly different from the yield of $43 \%(336 / 813 ; P=.08)$ in patients without prior antibiotic exposure.

LIMITATIONS: The conclusions of this meta-analysis are primarily limited by the heterogeneity of the included studies.

CONCLUSIONS: Image-guided biopsy has a moderate yield for the diagnosis of infectious discitis, which is significantly lower than the yield of open surgical biopsy. This yield is not significantly affected by prior antibiotic use.

D iscitis (also referred to as vertebral osteomyelitis, spondylitis, or spondylodiscitis) is an infectious process of the disc space and/or associated vertebral body. The reported incidence ranges between 4-24 per million per year ${ }^{1}$ and has been increasing over recent years because of intravenous drug use, immunocompromised hosts, and the increasing use of spinal instrumentation and surgery. ${ }^{2}$ The infection can be classified as granulomatous (tuberculosis and other mycobacterial pathogens) or

Received March 31, 2017; accepted after revision June 7.

From the University of Michigan Health System (A.L.M., D.M.G.-H., S.K.C., A.S.), Ann Arbor, Michigan; and University of California, San Francisco (E.C.D.), San Francisco, California.

Abstract previously presented at: Radiological Society of North America Scientific Assembly and Annual Meeting, November 27 to December 2, 2016; Chicago, llinois.

Please address correspondence to Alyssa McNamara, MD, 1500 E Medical Center Dr, Ann Arbor, MI 48109; e-mail: alyssamcn@gmail.com

$\square$ Indicates article with supplemental on-line photos.

http://dx.doi.org/10.3174/ajnr.A5337 pyogenic ${ }^{1}$; the most common pyogenic infectious agent is Staphylococcus aureus. ${ }^{3}$

Clinical presentation of discitis involves the insidious onset of constant back pain with neurologic deficits in one-third of cases. ${ }^{2}$ Diagnosis is often delayed because of the nonspecific symptoms and results in prolonged morbidity and poorer clinical outcomes including prolonged neurologic deficits. ${ }^{2}$ Treatment generally consists of antibiotics for 6-8 weeks, with surgical debridement necessary in cases of compression of neurologic structures or failure of antibiotic therapy. ${ }^{4}$

The diagnosis of discitis can be made based on a combination of clinical signs, laboratory tests, and imaging. Clinical signs include elevated white blood cell count, persistent low back pain, and laboratory tests including elevated C-reactive protein and erythrocyte sedimentation rate as well as positive blood cultures. ${ }^{1,2}$ The clinical standard imaging technique is contrast-enhanced MR imaging, particularly early in the disease process. ${ }^{1,2,5}$ MR imaging has a high sensitivity (96\%) and specificity (92\%) for discitis. ${ }^{6}$ Typical MR imaging findings include an increase in fluid 
Pubmed Search Terms

1. Discitis[mh] OR discitis[tiab] OR diskitis[tiab] OR discitides[tiab] OR diskitides[tiab]

2. Spondylodiskitis[tiab] OR spondylodiskitides[tiab] OR spondylodiscitis[tiab] OR spondylodiscitides[tiab] OR spondylitis[tiab]

3. \#1 OR \#2

4. Spine[mh] OR spine[tiab] OR spinal[tiab] OR vertebra*[tiab]

5. Osteomyelitis[mh] OR osteomyelitis[tiab] OR osteomyelitides[tiab]

6. Biopsy[mh] OR biopsy[tiab] OR biopsies[tiab] OR aspirat*[tiab]

7. (\#4 AND \#5)

8. \#3 OR \#7

9. \#8 AND \#6

\section{Literature Search:}

Pubmed, Embase, CENTRAL Cochrane, Scopus

Potentially relevant sources $(n=1814)$

Excluded by title and abstract screen $(n=1726)$

Full text unable to be retrieved $(n=2)$

Full text retrieved and assessed $(\mathrm{n}=86)$

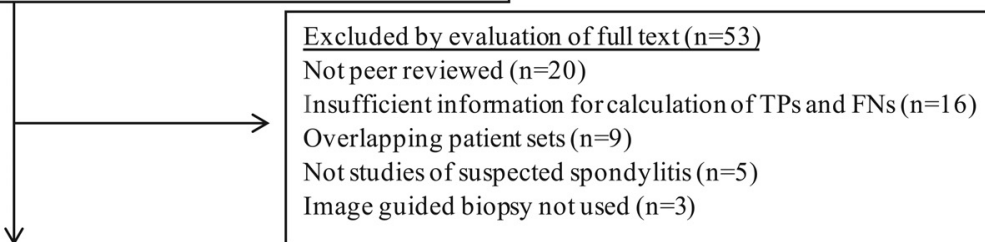

Studies included in systematic review $(n=33)$

FIG 1. PubMed search structure and search flow diagram. Mh indicates Medical Subject Heading; tiab, Title and Abstract; TP, true-positive; FN, false-negative.

signal on T2-weighted sequences and postcontrast enhancement of the disc, vertebral bodies, or the surrounding soft tissues. ${ }^{7}$

When clinical findings are suggestive of discitis, but blood cultures are negative, microbiologic confirmation through direct biopsy is a frequently used subsequent diagnostic strategy. ${ }^{3}$ Microbiologic diagnosis allows for confirmation of the diagnosis of infectious discitis as well as identification of the microorganism to tailor antibiotic therapy. The reported sensitivity of biopsy has ranged widely within the literature between $31 \%$ and $91 \% .^{8-9}$ Lower sensitivity has been associated with antibiotic use and percutaneous rather than surgical biopsy. ${ }^{10-14}$ Current Infectious Diseases Society of America guidelines recommend percutaneous biopsy in cases of suspected discitis without positive blood cultures and treating empirically in cases of positive blood cultures. ${ }^{3}$ In cases of negative percutaneous biopsy, Infectious Diseases Society of America guidelines recommend repeating the image-guided biopsy or proceeding to surgical biopsy to improve sensitivity. ${ }^{3}$

Given the broad range of reported sensitivity in the literature, the current study aimed to evaluate the literature with regard to the yield of image-guided biopsy in suspected cases of discitis. We performed a systematic review of image-guided biopsy in suspected cases of discitis. We identified 1 other systematic review and meta-analysis on this topic, performed by Pupaibool et al, ${ }^{15}$ which found the sensitivity of CT-guided biopsy to be $52.2 \%$, though this meta-analysis did not consider cases of discitis with prior surgical intervention (a common and clinically important indication for image-guided biopsy), did not assess many subgroups, and evaluated only 358 abstracts as opposed to the 1814 abstracts we identified as potentially relevant. In our study, the studies were compared in a meta-analysis of sensitivity, as well as the following subgroup analyses: open surgical versus image-guided biopsy, prior antibiotic exposure, type of image guidance, biopsy technique, pathogen detected, and pathogen detection technique (polymerase chain reaction versus culture).

\section{MATERIALS AND METHODS Protocol and Registration}

A review protocol was designed according to PRISMA guidelines and registered with the PROSPERO register (ID CRD42016039121).

\section{Eligibility Criteria}

Eligible studies were peer-reviewed journal articles containing empiric data on the yield of image-guided biopsy in discitis. The inclusion criteria were as follows: a) peer-reviewed journal publication on human patients; b) patients were clinically suspected of having infectious discitis before biopsy; c) biopsy samples were obtained via CT- or fluoroscopic-guided procedure; and d) reported data necessary to extract true-positive and falsenegative biopsy culture results.

\section{Search}

An experienced reference librarian assisted with designing the search strategy. The search strategy was designed with synonyms identified through index searching with MeSH. The following electronic data bases were searched: PubMed, Cochrane CENTRAL Register of Controlled Trials, Embase.com, and Scopus. The search was open to articles from data base inception to March 3, 2016 and was not restricted to the English language. An example of the search structure used in PubMed is illustrated in Fig 1.

\section{Study Selection}

The title/abstract screening was completed independently by 2 reviewers with DistillerSR (Evidence Partners, Cambridge, United Kingdom). Disagreements were resolved by consensus discussion between the 2 reviewers. Non-English literature was translated with Google Translate (Google, Mountain View, California). The full-text articles of relevant references were acquired and independently reviewed for inclusion. Disagreements were resolved by consensus discussion by the 2 reviewers. 


\begin{tabular}{|c|c|c|c|c|c|c|c|c|c|c|c|}
\hline Author & Year & $\begin{array}{l}\text { Reference } \\
\text { Standard }^{\mathrm{a}}\end{array}$ & $\begin{array}{l}\text { Image } \\
\text { Guidance }\end{array}$ & $\begin{array}{c}\text { Biopsy } \\
\text { Type }\end{array}$ & Pathogens & $\begin{array}{c}\text { Prior } \\
\text { Antibiotics }\end{array}$ & TP & FN & FP & $\mathrm{TN}$ & $\begin{array}{c}\text { Total } \\
\text { Patients }\end{array}$ \\
\hline Spira et $\mathrm{al}^{21}$ & 2016 & MRI & CT & Core & Mixed & NR & 10 & 24 & & & 34 \\
\hline Agarwal et $\mathrm{al}^{5}$ & 2016 & Mixed & Mixed & Core & Mixed & Mixed & 30 & 94 & & & 124 \\
\hline Brinjikji et $\mathrm{al}^{22}$ & 2015 & MRI & Mixed & NR & Mixed & Mixed & 38 & 39 & & & 77 \\
\hline Kim et $\mathrm{al}^{23}$ & 2015 & NR & NR & NR & Pyogenic & None & 38 & 52 & & & 90 \\
\hline Chang et $\mathrm{al}^{18}$ & 2015 & Histopathology & $\mathrm{CT}$ & Core & Mixed & Mixed & 29 & 26 & 4 & 29 & 88 \\
\hline Garg et $\mathrm{al}^{24}$ & 2014 & Mixed & CT & Core & Mixed & Mixed & 16 & 68 & & & 84 \\
\hline Choi et $\mathrm{al}^{19}$ & 2014 & MRI & Mixed & NR & Mixed & Mixed & 12 & 32 & 1 & & 45 \\
\hline Tachibana et $\mathrm{al}^{25}$ & 2014 & NR & NR & NR & Pyogenic & NR & 11 & 17 & & & 28 \\
\hline Gras et $\mathrm{al}^{26}$ & 2014 & MRI & CT & NR & Pyogenic & None & 7 & 6 & & & 13 \\
\hline Aagaard et $\mathrm{a}^{27}$ & 2013 & Mixed & NR & NR & Pyogenic & NR & 59 & 77 & & & 136 \\
\hline Kim et $\mathrm{al}^{28}$ & 2013 & Mixed & Fluoroscopy & Core & Mixed & None & 51 & 83 & & & 134 \\
\hline Gasbarrini et $\mathrm{al}^{29}$ & 2012 & MRI & CT & Core & Mixed & None & 12 & 14 & & & 26 \\
\hline Cebrián Parra et $\mathrm{al}^{30}$ & 2012 & MRI & NR & NR & Mixed & NR & 10 & 14 & & & 24 \\
\hline Heyer et $\mathrm{al}^{31}$ & 2012 & Histopathology & CT & Core & Mixed & Mixed & 10 & 20 & & & 30 \\
\hline Nam et $\mathrm{al}^{32}$ & 2011 & Mixed & Mixed & NR & Mixed & Mixed & 28 & 28 & & & 56 \\
\hline Marschall et $\mathrm{al}^{13}$ & 2011 & MRI & Mixed & NR & Pyogenic & Mixed & 40 & 87 & & & 127 \\
\hline Shibayama et $\mathrm{al}^{33}$ & 2010 & NR & Fluoroscopy & FNA & Pyogenic & NR & 32 & 28 & & & 60 \\
\hline de Lucas et $\mathrm{al}^{34}$ & 2009 & Mixed & $\mathrm{CT}$ & FNA & Mixed & Mixed & 11 & 1 & & & 12 \\
\hline Yang et $\mathrm{al}^{12}$ & 2008 & Histopathology & CT & Core & Mixed & NR & 20 & 26 & & & 46 \\
\hline Michel et $\mathrm{al}^{35}$ & 2006 & MRI & CT & Core & Mixed & None & 15 & 17 & & & 32 \\
\hline Colmenero et $\mathrm{al}^{36}$ & 2004 & Mixed & Mixed & Core & Tuberculosis/mycobacterial & NR & 11 & 7 & & & 18 \\
\hline Ben Taarit et $\mathrm{al}^{37}$ & 2002 & Mixed & Mixed & NR & Pyogenic & NR & 12 & 13 & & & 25 \\
\hline Nolla et $\mathrm{al}^{17}$ & 2002 & Mixed & CT & NR & Pyogenic & Mixed & 25 & 16 & & & 41 \\
\hline Pertuiset et $\mathrm{al}^{39}$ & 1999 & Mixed & Fluoroscopy & NR & Tuberculosis/mycobacterial & NR & 11 & 10 & & & 21 \\
\hline Jiménez-Mejías et al ${ }^{11}$ & 1999 & Mixed & NR & NR & Pyogenic & NR & 4 & 2 & & & 6 \\
\hline Vinicoff et $\mathrm{al}^{40}$ & 1998 & NR & CT & Core & Pyogenic & NR & 38 & 12 & & & 50 \\
\hline Fouquet et $\mathrm{al}^{41}$ & 1996 & NR & NR & Core & Mixed & NR & 4 & 2 & & & 6 \\
\hline Bateman et $\mathrm{al}^{42}$ & 1995 & Mixed & NR & NR & NR & Mixed & 12 & 6 & & & 18 \\
\hline Al Soub et $\mathrm{al}^{43}$ & 1994 & Mixed & $\mathrm{CT}$ & NR & Mixed & NR & 52 & 31 & & & 83 \\
\hline Cotty et $\mathrm{al}^{44}$ & 1988 & NR & Fluoroscopy & Core & Mixed & Mixed & 19 & 9 & & & 28 \\
\hline Ernst $^{45}$ & 1984 & NR & Fluoroscopy & NR & Pyogenic & NR & 36 & 25 & & & 61 \\
\hline Seignon et $\mathrm{al}^{46}$ & 1980 & NR & NR & FNA & Mixed & NR & 16 & 4 & & & 20 \\
\hline Duquennoy et $\mathrm{al}^{47}$ & 1979 & NR & NR & FNA & Mixed & NR & 16 & 14 & & & 30 \\
\hline
\end{tabular}

Note:-FN indicates false-negative; FNA, fine needle aspiration; FP, false-positive; NR, not recorded in original study; TN, true-negative; TP, true-positive.

${ }^{a}$ All studies used clinical characteristics in addition to the reference standards listed.

\section{Data Collection Process}

Data were collected from the full text of the eligible studies by 1 reviewer. Extracted data included the publication year and number of patients, true-positives, true-negatives, false-positives, and false-negatives. Where possible, values were also recorded for the following factors potentially contributing to study heterogeneity: biopsy performed with a large-bore cutting or core needle versus fine needle aspiration, use of CT or fluoroscopic guidance for biopsy, antibiotic use before biopsy, type of pathogen responsible for discitis (pyogenic versus mycobacterial pathogen), and use of surgical biopsy when reported in the same paper. In cases of overlapping patient sets between separate publications, the most recent series was selected and included in the systematic review and meta-analysis.

\section{Risk of Bias in Individual Studies}

The risk of bias of each study was assessed by using the Quality Assessment of Diagnostic Accuracy Studies 2, or QUADAS-2, tool independently by 2 authors with disagreements resolved by discussion. QUADAS-2 is a tool composed of 4 domains: patient selection, index test, reference standard, and flow and timing. These domains are assessed in terms of risk of bias, and the first 3 domains are also assessed in terms of concerns regarding applicability. ${ }^{16}$

\section{Statistical Analysis}

Statistical analysis was performed in R 3.3.0 (http://www.rproject.org/) by using the "metaprop" and "forest" functions of the "meta" package, ${ }^{17}$ which generated confidence intervals of the proportion of true-positives (yield) as well as hypothesis testing with an inverse variance method after logit transformation. Results reported in this paper represent random-effects models of meta-analysis. Estimates of yield were produced with $95 \%$ confidence intervals. Values of $P<.05$ were regarded as significant.

\section{RESULTS}

\section{Study Selection}

The search results are shown in Fig 1. The literature search identified 1814 articles. An initial screen of the titles and abstracts identified 88 potentially relevant articles. Eighty-six of the relevant articles were obtainable, and 2 articles were unobtainable through our institution's resources or interlibrary loan. The 86 full-text relevant articles were reviewed for eligibility, and 33 articles satisfied all of the inclusion criteria. Reasons for exclusion of the 53 references are included in Fig 1. Data were extracted for 33 articles found to be eligible for inclusion in the systematic review and meta-analysis.

\section{Study Characteristics}

The individual study characteristics are presented in the Table. In total, there were 1763 image-guided biopsies with attempted culture for inclusion within the systematic review. The reference test for the diagnosis of discitis was established by a variety of methods across the studies: as an adjunct to clinical characteristics (which was used in all included studies); 13/33 (39\%) used a mix of CT 


\section{Study}

2016 Spira, et al

2016 Agarwal, et al

2015 Brinjikji, et al

$2015 \mathrm{Kim}$, et al

2015 Chang, et al

2014 Garg, et al

2014 Choi, et al

2014 Gras, et al

2014 Tachibana, et al

2013 Aagaard, et al

$2013 \mathrm{Kim}$, et al

2012 Gasbarrini, et al

2012 Cebrian Parra, et al

2012 Heyer, et al

$2011 \mathrm{Nam}$, et al

2011 Marschall, et al

2010 Shibayama, et al

2009 de Lucas, et al

2008 Yang, et al

2006 Michel, et al

2004 Colmenero, et al

2002 Ben Taarit, et al

2002 Nolla, et al

1999 Pertuiset et al

1999 Jimenez-Mejias, et al

1998 Vinicoff, et al

1996 Fouquet, et al

1995 Bateman, et al

1994 Al Soub, et al

1988 Cotty, et al

1984 Ernst

1980 Seignon, et al

1979 Duquennoy, et al

Random effects model

Random effects model
Heterogeneity: $I^{2}=77 \%, \tau^{2}=0.2893, p<0.01$
Events Total

$10 \quad 34$

$30 \quad 124$

$38 \quad 77$

$69 \quad 136$

2988

$16 \quad 84$

1245

$59 \quad 136$

713

1226

$51 \quad 134$

$10 \quad 24$

$40 \quad 127$

$\begin{array}{rr}40 & 127 \\ 10 & 30\end{array}$

3260

$11 \quad 12$

$20 \quad 46$

$\begin{array}{ll}15 & 32 \\ 11 & 18\end{array}$

1118

$\begin{array}{ll}12 & 25 \\ 25 & 41\end{array}$

$11 \quad 21$

3850

46

1218

5283

$\begin{array}{ll}19 & 30 \\ 16 & 20\end{array}$

1630

1128

$36 \quad 61$

$31 \quad 48$

01
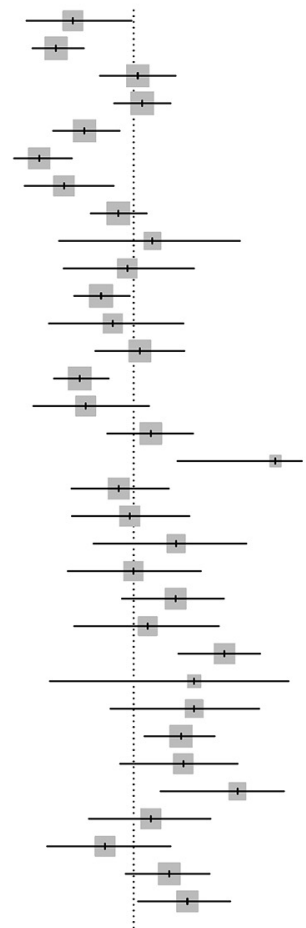

$\stackrel{1}{\vdots}$

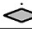

$\begin{array}{llll}0.2 & 0.4 & 0.6 & 0.8\end{array}$

FIG 2. Forest plot of overall yield of image-guided biopsy

and MR imaging; 8/33 (24\%) used MR imaging; 3/33 (9\%) used histopathology; and 9/33 (27\%) did not clearly define the specific imaging or other diagnostic tests. Few studies confirmed the use of coaxial guidance $(8 / 33$ [24\%]), whereas most did not report specifically on coaxial versus noncoaxial technique.

\section{Quality and Applicability Assessment}

The QUADAS-2 results of each individual study is represented in On-line Fig 1. The assessment showed that most studies had a low risk of bias with regard to flow and timing, index test, and patient selection, as shown in On-line Fig 2. Studies that required or included a positive biopsy culture, the index test, as a criterion for the diagnosis of discitis were considered to have a high risk of bias with respect to the reference standard. Studies that did not thoroughly describe the factors contributing to the diagnosis of discitis were considered to have an uncertain risk of bias regarding the reference standard. With regard to the selection of patients, studies that excluded postoperative discitis or patients with epidural abscesses were considered to have a high risk of bias. Studies that did not fully describe the methods of patient selection were considered to have an uncertain risk of bias with regard to patient selection.

\section{Meta-Analysis}

Yield was calculated by using the true-positive data and falsenegative data from each study. All but 2 studies did not report data for true-negatives and false-positives. ${ }^{18,19}$ In each of those studies, false-positive results were classified based on the growth of common contaminants without concurrent growth in blood cultures.

\section{Proportion $\quad 95 \%-\mathrm{Cl}$ Weight}

$0.29[0.15 ; 0.47] \quad 2.9 \%$

$0.24[0.17 ; 0.33] \quad 3.8 \%$

$0.49[0.38 ; 0.61] \quad 3.7 \%$

$0.51[0.42 ; 0.59] \quad 3.9 \%$

$0.33[0.23 ; 0.44] \quad 3.7 \%$

$0.19[0.11 ; 0.29] \quad 3.4 \%$

$0.27[0.15 ; 0.42] \quad 3.1 \%$

$0.43[0.35 ; 0.52] \quad 3.9 \%$

$0.54[0.25 ; 0.81] \quad 2.1 \%$

$0.46[0.27 ; 0.67] \quad 2.8 \%$

$0.38[0.30 ; 0.47] \quad 3.9 \%$

$0.42[0.22 ; 0.63] \quad 2.7 \%$

$0.50[0.36 ; 0.64] \quad 3.5 \%$

$0.31[0.24 ; 0.40] \quad 3.9 \%$

$0.33[0.17 ; 0.53] \quad 2.9 \%$

$0.53[0.40 ; 0.66] \quad 3.5 \%$

$0.92[0.62 ; 1.00] \quad 0.9 \%$

$0.43[0.29 ; 0.59] \quad 3.3 \%$

$0.47[0.29 ; 0.65] \quad 3.0 \%$

$0.61[0.36 ; 0.83] \quad 2.4 \%$

$0.48[0.28 ; 0.69] \quad 2.8 \%$

$0.61[0.45 ; 0.76] \quad 3.2 \%$

$0.52[0.30 ; 0.74] \quad 2.6 \%$

$0.76[0.62 ; 0.87] \quad 3.1 \%$

$0.67[0.22 ; 0.96] \quad 1.2 \%$

$0.67[0.41 ; 0.87] \quad 2.3 \%$

$0.63[0.51 ; 0.73] \quad 3.7 \%$

$0.63[0.44 ; 0.80] \quad 2.9 \%$

$0.80[0.56 ; 0.94] \quad 2.1 \%$

$0.53[0.34 ; 0.72] \quad 3.0 \%$

$0.39[0.22 ; 0.59] \quad 2.9 \%$

$0.59[0.46 ; 0.71] \quad 3.5 \%$

$0.65[0.49 ; 0.78] \quad 3.3 \%$

$0.48[0.43 ; 0.54] 100.0 \%$
The pooled yield of the 33 studies included in the meta-analysis was $48 \%$ (793/1763 patients; 95\% CI, 0.43-0.54 [Fig 2]). There were multiple sources of heterogeneity within the studies, including surgical biopsy, antibiotic exposure, CT or fluoroscopic guidance, large-bore and/or cutting needle biopsy versus fine needle aspiration, pyogenic versus mycobacterium tuberculosis, and polymerase chain reaction versus culture.

Eight studies included data from open surgical biopsy specimens, and the yield within this subgroup was significantly higher than image guided biopsy at 76\% (152/201; 95\% CI, 0.65-0.85; $P<.01$ [Fig 3]).

Twelve studies included patients with confirmed antibiotic exposure before image-guided biopsy, and 17 studies included patients with confirmed absence of antibiotic exposure before imageguided biopsy. Image-guided biopsy in patients without prior antibiotic exposure produced a higher yield at $43 \%$ (336/813; 95\% CI, 0.37-0.48; $P=.08$ ) compared with $32 \%(106 / 346 ; 95 \%$ CI, $0.22-0.43$ ) in the group with prior antibiotic exposure, though this was not statistically significant (On-line Fig 3).

Fourteen studies specified the number of biopsies performed under CT guidance, and 6 studies specified the number of biopsies performed under fluoroscopic guidance. All other studies either did not break down results by method or did not specify the method of image guidance. Fluoroscopic guidance was associated with a higher yield at 55\% (158/316; 95\% CI $0.40-0.69)$ compared with CT guidance at $44 \%(275 / 693 ; 95 \% \mathrm{CI}, 0.36-0.53 ; P=$ .22 ), though this was not statistically significant (On-line Fig 4 ).

Seventeen studies specified the use of cutting or core needle biopsy (large bore) or fine needle aspiration, with 13 studies using large-bore biopsy and 4 studies using fine needle aspiration. Fine needle aspiration was associated with a significantly higher yield at $60 \%(98 / 167 ; 95 \% \mathrm{CI}, 0.45-0.73)$ compared with large-bore needle biopsy at $41 \%(304 / 821 ; 95 \%$ CI, $0.33-0.49 ; P=.03$ [Online Fig 5]).

Seventeen studies reported data specific for pyogenic pathogen detection, and 7 studies reported data specific for mycobacterium tuberculosis detection. Image-guided biopsy had a significantly higher yield in the detection of mycobacterium tuberculosis at 71\% (97/132; 95\% CI, 0.54-0.84) compared with detection of pyogenic organisms at $48 \%(331 / 738 ; 95 \% \mathrm{CI}, 0.41-0.56 ; P=.02$ [On-line Fig 6]).

Two studies reported results for polymerase chain reaction detection of pathogen. There was no significant difference between the yield of polymerase chain reaction at 50\% (30/60; 95\% CI, $0.38-0.63)$ and culture at $48 \%$ (793/1763; 95\% CI, 0.43-0.54; $P=.46$ [On-line Fig 7]). 
Image Guided Biopsy

2016 Spira, et al

2016 Agarwal, et al

2015 Brinjikji, et al

$2015 \mathrm{Kim}$, et al

2015 Chang, et al

2014 Garg, et al

2014 Choi, et al

2014 Gras, et al

2014 Tachibana, et al

2013 Aagaard, et al

$2013 \mathrm{Kim}$, et al

2012 Gasbarrini, et al

2012 Cebrian Parra, et al

2012 Heyer, et al

2011 Nam, et al

2011 Marschall, et al

2010 Shibayama, et al

2009 de Lucas, et al

2008 Yang, et al

2006 Michel, et al

2004 Colmenero, et al

2002 Nolla, et al

2002 Ben Taarit, et

1999 Pertuiset, et al

1999 Jimenez-Mejias, et al

1998 Vinicoff, et al

1996 Fouquet, et al

1995 Bateman, et al

1994 Al Soub, et al

1988 Cotty, et al

1984 Ernst

1980 Seignon, et al

1979 Duquennoy, et al

Random effects mode

Heterogeneity: $I^{2}=77 \%, \tau^{2}=0.2893, p<0.01$

\section{Open surgical biopsy}

2013 Aagaard, et al

$2011 \mathrm{Nam}$, et al

2011 Marschall, et al

2004 Colmenero, et al

2002 Nolla, et al

1999 Pertuiset, et al

1999 Jimenez-Mejias, et al

Random effects model
2008 Yang, et al
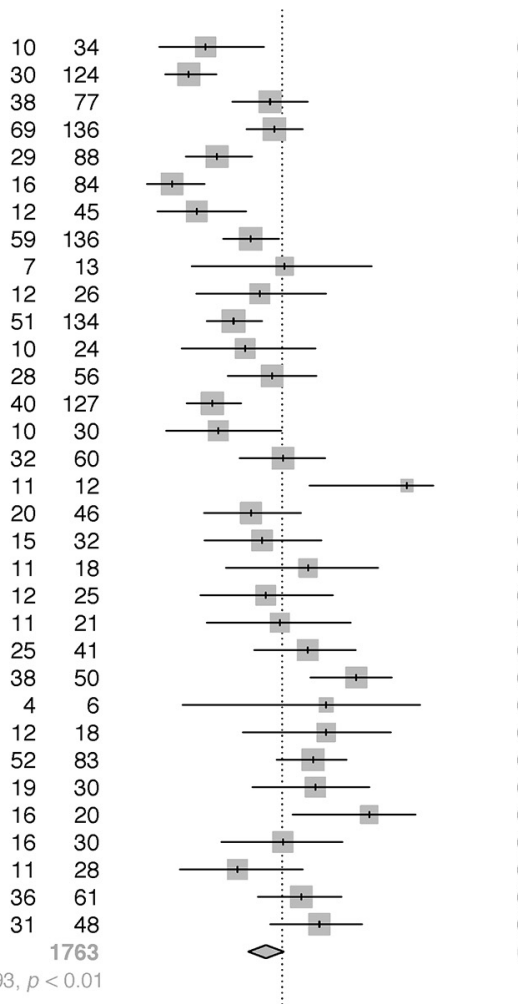

$0.29[0.15 ; 0.47] \quad 2.5 \%$

$0.24[0.17 ; 0.33] \quad 3.1 \%$

$0.49[0.38 ; 0.61] \quad 3.0 \%$

$0.51[0.42 ; 0.59] \quad 3.2 \%$

$0.33[0.23 ; 0.44] \quad 3.0 \%$

$0.19[0.11 ; 0.29] \quad 2.9 \%$

$0.27[0.15 ; 0.42] \quad 2.7 \%$

$0.43[0.35 ; 0.52] \quad 3.2 \%$

$0.54[0.25 ; 0.81] \quad 1.9 \%$

$0.46[0.27 ; 0.67] \quad 2.5 \%$

$0.38[0.30 ; 0.47] \quad 3.2 \%$

$0.42[0.22 ; 0.63] \quad 2.4 \%$

$0.50[0.36 ; 0.64] \quad 2.9 \%$

$0.31[0.24 ; 0.40] \quad 3.1 \%$

$0.33[0.17 ; 0.53] \quad 2.5 \%$

$0.53[0.40 ; 0.66] \quad 2.9 \%$

$0.92[0.62 ; 1.00] \quad 0.9 \%$

$0.43[0.29 ; 0.59] \quad 2.8 \%$

$0.47[0.29 ; 0.65] \quad 2.6 \%$

$0.61[0.36 ; 0.83] \quad 2.1 \%$

$0.48[0.28 ; 0.69] \quad 2.4 \%$

$0.52[0.30 ; 0.74] \quad 2.3 \%$

$0.61[0.45 ; 0.76] \quad 2.7 \%$

$0.76[0.62 ; 0.87] \quad 2.7 \%$

$0.67[0.22 ; 0.96] \quad 1.2 \%$

$0.67[0.41 ; 0.87] \quad 2.1 \%$

$0.63[0.51 ; 0.73] \quad 3.0 \%$

$0.63[0.44 ; 0.80] \quad 2.5 \%$

$0.80[0.56 ; 0.94] \quad 1.9 \%$

$0.53[0.34 ; 0.72] \quad 2.6 \%$

$0.39[0.22 ; 0.59] \quad 2.5 \%$

$0.59[0.46 ; 0.71] \quad 2.9 \%$

$0.65[0.49 ; 0.78] \quad 2.8 \%$

$0.48[0.43 ; 0.54] \quad 85.0 \%$

$0.60[0.42 ; 0.76] \quad 2.6 \%$

$0.70[0.50 ; 0.86] \quad 2.4 \%$

$0.91[0.75 ; 0.98] \quad 1.8 \%$

$0.90[0.68 ; 0.99] \quad 1.4 \%$

$0.62[0.45 ; 0.78] \quad 2.7 \%$

$0.75[0.51 ; 0.91] \quad 2.0 \%$

$0.81[0.54 ; 0.96] \quad 1.7 \%$

$1.00[0.77 ; 1.00] \quad 0.5 \%$

$0.76[0.65 ; 0.85] \quad 15.0 \%$

$0.53[0.47 ; 0.59] 100.0 \%$

Test for subgroup differences: $\chi_{1}=17.46, \mathrm{df}=1(p<0.01)$ to provide antibiotics before obtaining a positive culture result is a complex clinical decision that must weigh diagnostic certainty and decisive antibiotic selection against the benefits of early therapy.

Although this meta-analysis suggests fluoroscopy-guided biopsy had a higher yield of 55\% compared with $44 \%$ for CT-guided biopsy, this difference did not reach statistical significance. The reasons for this are not clear. Intuitively, CT should provide better identification of the exact biopsy location compared with fluoroscopy. Most of the studies did not provide information regarding the location of biopsy (central versus peripheral) in all of the patients. This result may reflect the heterogeneity of confounding factors in the source studies (changing use of CT versus fluoroscopic guidance, etc). Alternatively, fluoroscopically guided biopsies may have had the needle placed more centrally than CT-guided biopsies; this could have provided more reassurance to the fluoroscopic operators that the needle was indeed within the disc compared with the CT operators, who may have stopped when the needle entered the peripheral disc because they were certain of the needle position.

There were several other sources of heterogeneity within the studies, suggesting other predictors of yield. Fine needle aspiration was associated with a higher yield of $60 \%$ compared with large-bore needle biopsy at $41 \%$. This is also counterintuitive, though fine needle aspiration may be used more frequently in cases of abscesses, which may yield a sample more likely to grow in cul-

\section{DISCUSSION}

At most institutions, image-guided biopsy is routinely conducted in patients with suspected discitis because it is considered important to identify the target microorganism before appropriate therapy can be administered. We undertook this meta-analysis to estimate the yield of image-guided biopsy and to better understand the factors that influence the yield of image-guided biopsy.

Our comprehensive meta-analysis demonstrates that image guided biopsy has a moderate yield of 48\% (95\% CI, 0.43-0.54) for the diagnosis of infectious discitis, providing a more useful assessment of this diagnostic tool than the broad range of $31 \%$ to $91 \%$ that has been reported in the literature. ${ }^{8,9}$ This yield is lower than open surgical biopsy (yield of $76 \%$ ), consistent with other reports in the literature. ${ }^{11,12}$ Prior antibiotic treatment causes a decrease in the yield of image-guided biopsy (43\% without prior antibiotics versus 32\% with prior antibiotic exposure), though this effect was statistically insignificant in this study. The decision ture. There were many studies that examined the detection of mycobacterium tuberculosis through culture, which was associated with a higher yield of $71 \%$, compared with the detection of pyogenic organisms with a yield of $48 \%$. Lastly, there was no significant difference in the yield of polymerase chain reaction at $50 \%$ compared with culture, but this may be as a result of only a small number of cases with polymerase chain reaction $(n=60)$ being assessed.

Most (31/33) of the examined studies considered all positive culture results from image-guided biopsies to be true-positives, essentially ignoring the possibility of false-positive results caused by factors such as surface or laboratory contamination. Two assessed studies acknowledged false-positive biopsy results. This assumption reflects the difficulty of demonstrating the responsible microorganism through reference diagnostic tests aside from direct biopsy, but may reflect a substantial error in research assess- 
ments of the performance of image-guided biopsy and many other scenarios of ongoing infectious disease research.

There is 1 other meta-analysis on the yield of image-guided biopsy in discitis, performed by Pupaibool et al, ${ }^{15}$ which demonstrated a yield of $52.2 \%$. We performed this meta-analysis because the study by Pupaibool et $\mathrm{al}^{15}$ had several limitations. Pupaibool et $\mathrm{al}^{15}$ excluded all studies of nonspontaneous discitis and included data from only 5 studies. Because spinal instrumentation and surgery are major contributors to cases of discitis and a high proportion of requests for image-guided biopsies involve patients post-instrumentation, we felt it was important to include these studies in our review and have evaluated the data from a much larger cohort of studies $(n=33) .{ }^{20}$ In addition, our study provides further diagnostic information through the subgroup analyses on the sources of heterogeneity, including open surgical biopsy, antibiotic therapy, and CT versus fluoroscopic guidance. From a methodology standpoint, our search strategy identified a higher number of potentially applicable abstracts (1814 versus 358).

There are some limitations to our analysis. Like all meta-analyses, the conclusions of this meta-analysis are primarily limited by the heterogeneity of the included studies. Specifically, the studies varied in the extent to which they described their methods, including coaxial needle, prior antibiotic exposure, first or repeat biopsy, number of samples collected, and prior imaging studies. The methodology of the meta-analysis itself was limited by the inability to obtain 2 potentially relevant references for full-text review.

\section{CONCLUSIONS}

This study indicates that image-guided biopsy in suspected discitis has a yield for detection of the infectious organism of $48 \%$, toward the lower end of the frequently reported range of $31 \%-$ $91 \% .^{3,8}$ Open surgical biopsy has a higher yield at $76 \%$, and antibiotic treatment had an insignificant effect on the yield.

\section{ACKNOWLEDGMENTS}

The authors thank Mark MacEachern, who provided guidance in designing the literature search strategy. We also thank Dr. Bin Nan for assistance with statistical analysis.

\section{REFERENCES}

1. Gouliouris T, Aliyu SH, Brown NM. Spondylodiscitis: update on diagnosis and management. J Antimicrob Chemother 2010;65(Suppl 3):iii11-24 CrossRef Medline

2. Mylona E, Samarkos M, Kakalou E, et al. Pyogenic vertebral osteomyelitis: a systematic review of clinical characteristics. Semin Arthritis Rheum 2009;39:10-17 CrossRef Medline

3. Berbari EF, Kanj SS, Kowalski TJ, et al. 2015 Infectious Diseases Society of America (IDSA) clinical practice guidelines for the diagnosis and treatment of native vertebral osteomyelitis in adults. Clin Infect Dis 2015;61:e26-46 CrossRef Medline

4. Rutges JP, Kempen DH, van Dijk M, et al. Outcome of conservative and surgical treatment of pyogenic spondylodiscitis: a systematic literature review. Eur Spine J 2016;25:983-99 CrossRef Medline

5. Agarwal V, Wo S, Lagemann GM, et al. Image-guided percutaneous disc sampling: impact of antecedent antibiotics on yield. Clin Radiol 2016;71:228-34 CrossRef Medline

6. Modic MT, Feiglin DH, Piraino DW, et al. Vertebral osteomyelitis: assessment using MR. Radiology 1985;157:157-66 CrossRef Medline
7. Cheung WY, Luk KD. Pyogenic spondylitis. Int Orthop 2012;36:397404 CrossRef Medline

8. Sehn JK, Gilula LA. Percutaneous needle biopsy in diagnosis and identification of causative organisms in cases of suspected vertebral osteomyelitis. Eur J Radiol 2012;81:940 - 46 CrossRef Medline

9. Chew FS, Kline MJ. Diagnostic yield of CT-guided percutaneous aspiration procedures in suspected spontaneous infectious diskitis. Radiology 2001;218:211-14 CrossRef Medline

10. Grados F, Lescure FX, Senneville E, et al. Suggestions for managing pyogenic (non-tuberculous) discitis in adults. Joint Bone Spine 2007; 74:133-39 CrossRef Medline

11. Jiménez-Mejías ME, de Dios Colmenero J, Sánchez-Lora FJ, et al. Postoperative spondylodiskitis: etiology, clinical findings, prognosis, and comparison with nonoperative pyogenic spondylodiskitis. Clin Infect Dis 1999;29:339-45 CrossRef Medline

12. Yang SC, Fu TS, Chen $\mathrm{LH}$, et al. Identifying pathogens of spondylodiscitis: percutaneous endoscopy or CT-guided biopsy. Clin Orthop Relat Res 2008;466:3086-92 CrossRef Medline

13. Marschall J, Bhavan KP, Olsen MA, et al. The impact of prebiopsy antibiotics on pathogen recovery in hematogenous vertebral osteomyelitis. Clin Infect Dis 2011;52:867-72 CrossRef Medline

14. Rankine JJ. Therapeutic impact of percutaneous spinal biopsy in spinal infection. Postgrad Med J 2004;80:607-09 CrossRef Medline

15. Pupaibool J, Vasoo S, Erwin PJ, et al. The utility of image-guided percutaneous needle aspiration biopsy for the diagnosis of spontaneous vertebral osteomyelitis: a systematic review and meta-analysis. Spine J 2015;15:122-31 CrossRef Medline

16. Whiting PF, Rutjes AW, Westwood ME, et al. QUADAS-2: a revised tool for the quality assessment of diagnostic accuracy studies. Ann Intern Med 2011;155:529-36 CrossRef Medline

17. Schwarzer G. General Package for Meta-Analysis. 2015

18. Chang CY, Simeone FJ, Nelson SB, et al. Is biopsying the paravertebral soft tissue as effective as biopsying the disk or vertebral endplate? 10-year retrospective review of CT-guided biopsy of diskitisosteomyelitis. AJR Am J Roentgenol 2015;205:123-29 CrossRef Medline

19. Choi SH, Sung H, Kim SH, et al. Usefulness of a direct $16 \mathrm{~S}$ rRNA gene PCR assay of percutaneous biopsies or aspirates for etiological diagnosis of vertebral osteomyelitis. Diagn Microbiol Infect Dis 2014; 78:75-78 CrossRef Medline

20. Gasbarrini A, Bertoldi E, Mazzetti M, et al. Clinical features, diagnostic and therapeutic approaches to haematogenous vertebral osteomyelitis. Eur Rev Med Pharmacol Sci 2005;9:53-66 Medline

21. Spira D, Germann T, Lehner B, et al. CT-guided biopsy in suspected spondylodiscitis-the association of paravertebral inflammation with microbial pathogen detection. PLoS One 2016;11:e0146399 CrossRef Medline

22. Brinjikji W, Everist B, Wald J, et al. Association between imaging findings and microbiological findings for image-guided biopsies for spine infections. J Neurosurg Sci 2015 Sep 9. [Epub ahead of print] Medline

23. Kim CJ, Kang SJ, Choe PG, et al. Which tissues are best for microbiological diagnosis in patients with pyogenic vertebral osteomyelitis undergoing needle biopsy? Clin Microbiol Infect 2015;21:931-35 CrossRef Medline

24. Garg V, Kosmas C, Young PC, et al. Computed tomography-guided percutaneous biopsy for vertebral osteomyelitis: a department's experience. Neurosurg Focus 2014;37:E10 CrossRef Medline

25. Tachibana T, Moriyama T, Maruo K, et al. Therapeutic impact of organism isolation in management of patients with pyogenic vertebral osteomyelitis. Springerplus 2014;3:62 CrossRef Medline

26. Gras G, Buzele R, Parienti JJ, et al. Microbiological diagnosis of vertebral osteomyelitis: relevance of second percutaneous biopsy following initial negative biopsy and limited yield of post-biopsy blood cultures. Eur J Clin Microbiol Infect Dis 2014;33:371-75 CrossRef Medline

27. Aagaard T, Roed C, Dragsted C, et al. Microbiological and therapeutic challenges in infectious spondylodiscitis: a cohort study of 100 
cases, 2006-2011. Scand J Infect Dis 2013;45:417-24 CrossRef Medline

28. Kim BJ, Lee JW, Kim SJ, et al. Diagnostic yield of fluoroscopyguided biopsy for infectious spondylitis. AJNR Am J Neuroradiol 2013;34:233-38 CrossRef Medline

29. Gasbarrini A, Boriani L, Salvadori C, et al. Biopsy for suspected spondylodiscitis. Eur Rev Med Pharmacol Sci 2012;16 Suppl 2:26-34 Medline

30. Cebrián Parra JL, Saez-Arenillas Martín A, Urda Martínez-Aedo AL, et al. Management of infectious discitis. Outcome in one hundred and eight patients in a university hospital. Int Orthop 2012;36: 239-44 CrossRef Medline

31. Heyer CM, Brus LJ, Peters SA, et al. Efficacy of CT-guided biopsies of the spine in patients with spondylitis-an analysis of 164 procedures. Eur J Radiol 2012;81:e244-49 CrossRef Medline

32. Nam KH, Song GS, Han IH, et al. Diagnostic value of biopsy techniques in lumbar spondylodiscitis: percutaneous needle biopsy and open biopsy. Korean J Spine 2011;8:267-71 CrossRef Medline

33. Shibayama M, Nagahara M, Kawase G, et al. New needle biopsy technique for lumbar pyogenic spondylodiscitis. Spine (Phila $\mathrm{Pa}$ 1976) 2010;35:E1347-49 CrossRef Medline

34. de Lucas EM, González Mandly A, Gutiérrez A, et al. CT-guided fineneedle aspiration in vertebral osteomyelitis: true usefulness of a common practice. Clin Rheumatol 2009;28:315-20 CrossRef Medline

35. Michel SC, Pfirrmann CW, Boos N, et al. CT-guided core biopsy of subchondral bone and intervertebral space in suspected spondylodiskitis. AJR Am J Roentgenol 2006;186:977-80 CrossRef Medline

36. Colmenero JD, Jiménez-Mejías ME, Reguera JM, et al. Tuberculous vertebral osteomyelitis in the new millennium: still a diagnostic and therapeutic challenge. Eur J Clin Microbiol Infect Dis 2004;23: 477-83 CrossRef Medline

37. Ben Taarit Ch, Turki S, Maiz H. Infectious spondylitis. Study of a series of 151 cases. [Article in French] Acta Orthop Belg 2002;68: 381-87 Medline

38. Nolla JM, Ariza J, Gómez-Vaquero C, et al. Spontaneous pyogenic vertebral osteomyelitis in nondrug users. Semin Arthritis Rheum 2002;31:271-78 CrossRef Medline

39. Pertuiset E, Beaudreuil J, Lioté F, et al. Spinal tuberculosis in adults. A study of 103 cases in a developed country, 1980-1994. Medicine 1999;78:309-20 CrossRef Medline

40. Vinicoff P, Gutschik E, Hansen S, et al. CT-guided biopsy in spondy lodiscitis. [Article in Danish] Ugeskr Laeger 1998;160:5931-34 Medline

41. Fouquet B, Goupille P, Gobert F, et al. Infectious discitis diagnostic contribution of laboratory tests and percutaneous discovertebral biopsy. Rev Rhum Engl Ed 1996;63:24-29 Medline

42. Bateman JL, Pevzner MM. Spinal osteomyelitis: a review of 10 years' experience. Orthopedics 1995;18:561-65 Medline

43. Al Soub H, Uwaydah AK, Hussain AH. Vertebral osteomyelitis in Qatar. Br J Clin Pract 1994;48:130-32 Medline

44. Cotty PH, Fouquet B, Pleskof L, et al. Vertebral osteomyelitis: value of percutaneous biopsy: 30 cases. J Neuroradiol 1988;15:13-21

45. Ernst $H$. Der diagnostische wer der wirbel-korperpunktion bei der spondylitis. Orthopadie 1984;34:443-47

46. Seignon B, Weilbacher H, Thorel J, et al. Spinal puncture in the bacteriological diagnosis of bacterial spondylitis. Experience in the rheumatology departments of Reims, Clermont-Ferrand and Rouen. [Article in French] Rev Rhum Mal Osteoartic 1980;47:45-47 Medline

47. Duquennoy A, Delcambre B, Duquesnoy B, et al. Value of disk puncture in the diagnosis of infectious spondylodiskitis. Apropos of 48 punctures. [Article in French] Rev Rhum Mal Osteoartic 1979;46: 615-17 Medline 